UNIVERSIDADE DE SÃO PAULO

INSTITUTO DE PSICOLOGIA

MILENA OSHIRO

O brincar na infância das crianças com deficiência:

um estudo exploratório

São Paulo 


\section{MILENA OSHIRO}

O brincar na infância das crianças com deficiência:

um estudo exploratório

Dissertação apresentada ao Instituto de Psicologia da Universidade de São Paulo, como requisito para obtenção do título de Mestre em Psicologia.

Área de Concentração: Psicologia Escolar e do Desenvolvimento Humano.

Orientadora: Profa ${ }^{a}$ Dra . Edda Bomtempo.

São Paulo 
AUTORIZO A REPRODUÇÃO E DIVULGAÇÃO TOTAL OU PARCIAL DESTE TRABALHO, POR QUALQUER MEIO CONVENCIONAL OU ELETRÔNICO, PARA FINS DE ESTUDO E PESQUISA, DESDE QUE CITADA A FONTE.

Catalogação na publicação Biblioteca Dante Moreira Leite Instituto de Psicologia da Universidade de São Paulo

Oshiro, Milena.

O brincar na infância das crianças com deficiência: um estudo exploratório / Milena Oshiro; orientadora Edda Bomtempo. -- São Paulo, 2010.

$125 \mathrm{f}$.

Dissertação (Mestrado - Programa de Pós-Graduação em Psicologia. Área de Concentração: Psicologia Escolar e do Desenvolvimento Humano) - Instituto de Psicologia da Universidade de São Paulo.

1. Recreação 2. Deficientes 3. Atividades cotidianas 4. Crianças I. Título. 
OSHIRO, M. O brincar na infância das crianças com deficiência: um estudo exploratório. Dissertação apresentada ao Instituto de Psicologia da Universidade de São Paulo para obtenção do título de Mestre em Psicologia.

Aprovado em:

Banca Examinadora

Prof. Dr. Instituição:

Julgamento: Assinatura:

Prof. Dr. Instituição:

Julgamento: Assinatura:

Prof. Dr. Instituição:

Julgamento: Assinatura: 
A Deus e aos Meus Pais.

À Melissa, Julio, Rafael

e a todas as crianças que me deram a oportunidade de brincar. 


\section{AGRADECIMENTOS}

À Professora Edda Bomtempo, por me dar a possibilidade de fazer desta pesquisa uma brincadeira compartilhada.

Ao Instituto de Psicologia, em especial ao Departamento de Psicologia Escolar e do Desenvolvimento Humano, pela oportunidade de realizar os meus estudos. À Profa. Audrey Setton Lopes de Souza, pelas discussões durante as disciplinas e pelas contribuições no exame de qualificação.

À APAE de São Paulo, pelo incentivo à pesquisa; em especial à Isa Mara Barraviera, pelo apoio em 2009. A toda a equipe do PIPA, em especial à Jô, Elaine, Nereide, Ariana e a todas as estagiárias de Terapia Ocupacional, pelas discussões e trocas de experiências. Também agradeço pelo carinho e pelo suporte, sempre presentes, junto com um brigadeiro ou um chocolate.

Ao PRISMA Arte \& Ensino, dos amigos Sebastião Miranda, Aurecy, Leila e Júnior, pelos encontros e pelas discussões apaixonadas, sempre alimento para a minha alma.

Às colegas da Secretaria Municipal de Educação de Itaquaquecetuba e do Hospital Maternidade Leonor Mendes de Barros, com carinho especial à Rosana de Souza e Andréia Yuriko Obana, pelo apoio profissional, mas, principalmente, pela amizade.

À Jô Benetton e à Sônia Ferrari, por me conduzirem e me instrumentalizarem para criar e re-criar a minha clínica. Às colegas do curso: Priscila, Fernanda, Gabriela, Patrícia e Josiane, pelos cinco anos de estudos e trilhas compartilhadas.

Às terapeutas ocupacionais Maria Conceição Santos e Celina Camargo Bartalotti, pela confiança refletida nas parcerias com o Centro Universitário São Camilo.

À Solange Tedesco e à Maria Madalena Moraes Sant'Anna, queridas professoras, por me acompanharem durante o curso de especialização em Lins. 
Às professoras Elizabeth M. F. de Araújo Lima e Eliane Dias de Castro e às colegas Rita de Abreu e Renata Mecca, por me receberem com carinho na disciplina "Atividades humanas, Cotidiano, Cultura e Terapia Ocupacional".

As pessoas que me ajudaram a realizar o trabalho: ao Hugo Calhau, pela transcrição cuidadosa das entrevistas; ao Jorge de Lima, pela revisão minunciosa da dissertação.

À Mirian Ribeiro Conceição, pelo companheirismo e solidariedade durante estes três anos de estudos.

À Marisa Takatori, por me ajudar nos primeiros passos da vida profissional e até hoje se fazer presente e constante.

Às terapeutas ocupacionais e amigas Hitomi, Renatinha e Neila, pelas histórias vividas, de perto e/ou à distância. Principalmente à Tiy e à Kika, por estarem ao meu lado durante a elaboração deste trabalho, seja para um incentivo, um café ou para as leituras da dissertação. A todas, por sempre torcerem por mim.

À Mari Brunello, pelo carinho e pela disposição em me ajudar na elaboração da dissertação. Mas, principalmente, por me orientar a viver a clínica antes de pesquisá-la; por ser um exemplo de que a VIDA deve ser vivida.

Às minhas irmãs Lucélia e Emine, pelo suporte emocional e operacional; pelas tortinhas de limão e pelos bolos quentinhos que ajudaram nos momentos difíceis.

Ao Mauricio, por estar sempre disponível a ler o trabalho, com atenção e bom humor; mas, principalmente, por entrar em minha vida e, com paciência e carinho, permanecer ao meu lado durante a composição da dissertação. 


\section{RESUMO}

OSHIRO, M. O brincar na infância das crianças com deficiência: um estudo exploratório. 2010. 125 f. Dissertação (Mestrado) - Instituto de Psicologia, Universidade de São Paulo, São Paulo, 2010.

Este trabalho propõe uma reflexão sobre o brincar na vida da criança que apresenta uma problemática intelectual, emocional e social. Destaca a Terapia Ocupacional e a contextualiza em relação aos temas presentes nas pesquisas que envolvem criança e deficiência: reabilitação e inclusão social. Apresenta a revisão da literatura sobre a infância e o brincar e delimita o recorte da Terapia Ocupacional: o brincar no cotidiano. Utilizando os fundamentos teóricos de Donald D. Winnicott, parte-se do pressuposto que o brincar é universal e próprio da infância saudável. A deficiência é entendida como uma problemática apresentada pela criança, seja física, intelectual, emocional e/ou social; ou seja, como mais uma das condições que a levará a estabelecer o seu jeito singular de brincar e estar no mundo. O trabalho caracterizase como uma pesquisa empírica, qualitativa, desenvolvida por meio de estudo de caso. A coleta de dados foi realizada na Associação de Pais e Amigos dos Excepcionais de São Paulo (APAE de São Paulo) através de análise dos prontuários e de entrevistas com as mães. O tratamento dos dados foi realizado a partir da técnica de análise de conteúdo, segundo as proposições de Turato (2003). Foram entrevistadas três mães de três crianças que participaram do Programa Arte, Cultura e Esporte da APAE de São Paulo, mais conhecido como projeto PIPA. As falas das mães retrataram a vivência da infância das crianças: brincar, ter amigos, ir à escola, participar de festas e passeios. Observou-se que, das três crianças estudadas, duas encontraram espaços em que brincar e conviver com os pares foi possível, participando da escola, festas e passeios; entretanto, a outra criança ainda tinha apenas o PIPA como lugar possível para brincar, fazendo com que sua mãe continue em busca de um espaço.

Palavras-chave: recreação, deficientes, atividades cotidianas, crianças. 


\begin{abstract}
OSHIRO, M. The experience of playing in childhood of children with disabilities: an exploratory study. 2010. 125 f. Dissertação (Mestrado) - Instituto de Psicologia, Universidade de São Paulo, São Paulo, 2010.

This work proposes a reflection about the playing experience to a child with intellectual, emotional and social problems. The study emphasizes the Occupational Therapy and contextualizes it in relation to themes of current researches involving children and disabilities: rehabilitation and social inclusion. Presenting a short revision of literature about childhood and play, this study gives the direction of Occupational Therapy intervention: the experience of playing in everyday life. Using the theoretical concepts of Donald D. Winnicott, it is understood that the act of playing is universal and characteristic of a healthy childhood. Disability is seen as a physical, intellectual, emotional and/or social problem presented by the child. It is seen as just one of the conditions that will establish their unique way of playing and being in the world. The investigation is an empirical and qualitative research, which uses the case study methodology. Data was collected at the Association of Parents and Friends of the Handicapped of São Paulo (APAE São Paulo) through examination of medical records and interviews with mothers. The data was analyzed through the technique of content analysis, according to the propositions of Turato (2003). Mothers of three children who took part in the Program Art, Culture and Sport of APAE, known as PIPA Project, were interviewed. They reported the childhood experiences of their children such as playing, making friends, going to school and parties. It was observed that two of the children have found spaces to play and socialize with peers, participating in school, parties and tours; however, one child had only the PIPA Project as a possible place to play, leading his mother to search for a new space.
\end{abstract}

Keywords: recreation, disabled children, activities of daily living, child. 
APAE

CID

CIDID

CIF

OMS

PIPA

TO

USP
Associação de Pais e Amigos dos Excepcionais

Classificação Estatística Internacional de Doenças e Problemas Relacionados à Saúde

Classificação Internacional das Deficiências, Incapacidades e Desvantagens

Classificação Internacional de Funcionalidade, Incapacidade e Saúde

Organização Mundial da Saúde

Projeto Inclusão pela Arte - Programa Arte, Cultura e Esporte

Terapia Ocupacional

Universidade de São Paulo 
SUMÁRIO

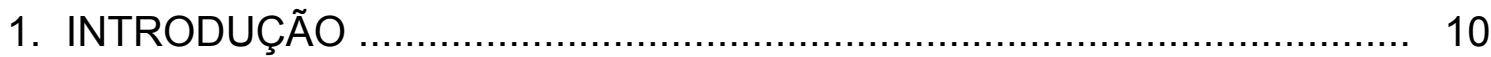

2. ENTRELAÇANDO DISCUSSÕES QUE ENVOLVEM A CRIANÇA COM DEFICIÊNCIA

3. INFÂNCIA: BRINCAR, TER AMIGOS, IR À ESCOLA...

4. BRINCAR

5. AS CONTRIBUIÇÕES DE WINNICOTT ............................................ 48

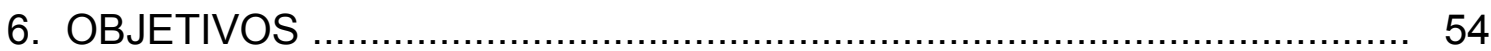

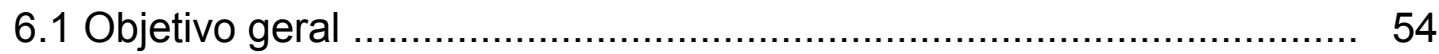

6.2 Objetivos específicos …………………………..................... 54

7. PROCEDIMENTOS METODOLÓGICOS ............................................ 55

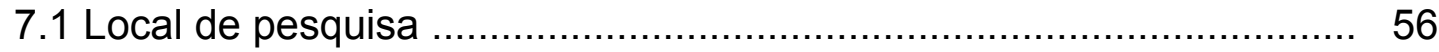

7.2 Sujeitos de Pesquisa ........................................................... 57

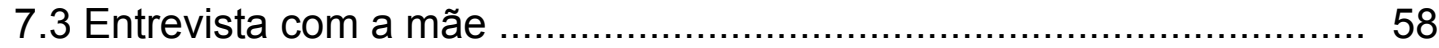

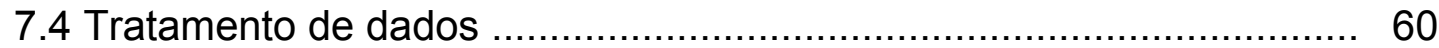

8. ANÁLISE DAS ENTREVISTAS E DISCUSSÃO: AS CRIANÇAS E O RETRATO DO BRINCAR NO COTIDIANO ............... 63

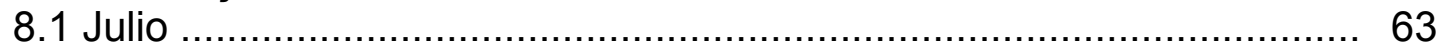

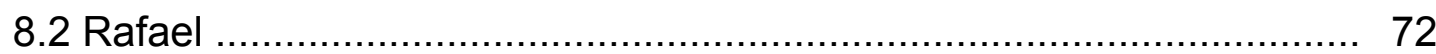

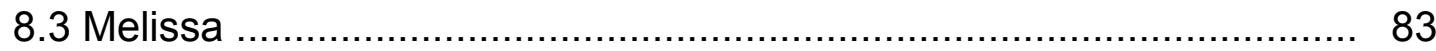

9. CONSIDERAÇÕES FINAIS ............................................................ 110

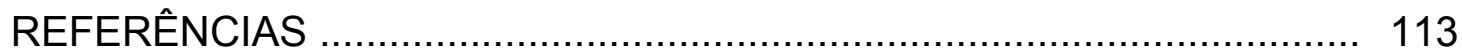

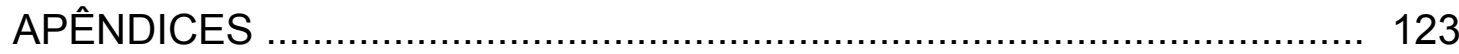

